\title{
Association between eNOS polymorphisms and risk of coronary artery disease in a Korean population: a meta-analysis
}

\author{
J.H. Sung ${ }^{1 *}$, B.E. Lee ${ }^{2 *}$, J.O. Kim², Y.J. Jeon ${ }^{2}$, S.H. Kim', S.W. Lim¹, J.Y. Moon', \\ D.H. Cha', O.J. Kim ${ }^{3}$, I.J. Kim ${ }^{1}$ and N.K. Kim ${ }^{2}$ \\ ${ }^{1}$ Department of Cardiology, CHA Bundang Medical Center, CHA University, \\ Seongnam, South Korea \\ 2Department of Biomedical Science, College of Life Science, CHA University, \\ Seongnam, South Korea \\ ${ }^{3}$ Department of Neurology, CHA Bundang Medical Center, CHA University, \\ Seongnam, South Korea \\ *These authors contributed equally to this study. \\ Corresponding authors: N.K. Kim / I.J. Kim \\ E-mail: nkkim@cha.ac.kr / injaikim@cha.ac.kr
}

Genet. Mol. Res. 14 (4): 16508-16520 (2015)

Received June 1, 2015

Accepted August 24, 2015

Published December 9, 2015

DOI http://dx.doi.org/10.4238/2015.December.9.23

ABSTRACT. Coronary artery disease (CAD), a multifactorial disease, is a common cause of mortality in humans. Polymorphisms in the endothelial nitric oxide synthase (eNOS) gene (-786T>C, 4a4b, and 894G>T) have been previously associated with increased CAD risk. However, the sample size of this previous study was too small and limited to comprehensively define an association between eNOS polymorphisms and CAD; therefore, this analysis was duplicated with a larger population. The study was conducted on 559 patients with CAD and 574 healthy controls. Genetic DNA was extracted using the commercial G-DEX blood extraction kit and statistical analyses were performed on the GraphPad prism 4.0 and MedCalc 12.0 statistical software platforms. No single variant of the eNOS 
polymorphism was associated with CAD risk. The combination genotypes of eNOS -786TT/4a4b+4a4a [adjusted odds ratio $(\mathrm{AOR})=0.122 ; 95 \%$ confidence interval $(\mathrm{Cl}): 0.042-0.358]$ and eNOS $-786 \mathrm{TC}+\mathrm{CC} / 4 \mathrm{~b} 4 \mathrm{~b}$ $(A O R=0.379 ; 95 \% \mathrm{Cl}: 0.147-0.979)$ were associated with decreased CAD incidence. Haplotype analysis revealed that the T-4a haplotype of eNOS $-786 \mathrm{~T}>\mathrm{C}$ and $4 \mathrm{a} 4 \mathrm{~b}$ exerted a protective effect against CAD. The association between eNOS -786T $>C$ and increased CAD risk was not replicated in this (larger) population. However, some combined genotypes showed a meaningful association with CAD risk.

Key words: Coronary artery disease; Polymorphism; Meta-analysis; Endothelial nitric oxide synthase; Haplotype; Korean

\section{INTRODUCTION}

According to the World Health Organization, coronary artery disease (CAD) is one of the most common causes of mortality (Cam et al., 2005). The classic risk factors that affect the induction and progression of CAD include age, gender, hypertension (HTN), diabetes mellitus (DM), and smoking (Chaer et al., 2004; Visvikis-Siest and Marteau, 2006).

One of the genes that contribute to CAD encodes the endothelial nitric oxide synthase (eNOS). Nitric oxide (NO), produced by eNOS, is synthesized from L-arginine in endothelial cells and platelets. NO plays an important roles in the maintenance of blood pressure and vascular tone (Huang et al., 1995; Ohashi et al., 1998). NO synthases have three isoforms; constitutive endothelial NOS (eNOS; NOS3), inducible NOS (iNOS; NOS2), and constitutive neuronal NOS (nNOS; NOS1) (Palmer, 1993; Gardemann et al., 2002). NO produced by eNOS diffuses from the endothelium to the vascular smooth muscle cells, where it increases the concentration of cyclic guanosine monophosphate (cGMP) and induces vascular relaxation by stimulating the soluble guanylate cyclase (Moncada and Higgs, 1993). eNOS maps to chromosome 7q35-36 (Marsden et al., 1993). A single nucleotide polymorphism (SNP) -786T>C in the $5^{\prime}$-flanking region of the eNOS gene results in reduced transcription factor binding and increased CAD risk (Miyamoto et al., 2000). Another polymorphism, intron 4 4a4b, has a variable number of tandem repeats (27 bp) in intron 4 (Wang et al., 1996). In this report, the designated 4a and $4 \mathrm{~b}$ alleles indicate a $27 \mathrm{bp}$ deletion and insertion in eNOS 4a4b, respectively. The 894G>T SNP, located in exon 7, substitutes aspartic acid for glutamine.

Several recent case-control studies have evaluated the roles of eNOS polymorphisms in CAD development (Tangurek et al., 2006; Rios et al., 2007; Han et al., 2010). The purpose of this study is to replicate previously published data in a larger population (Kim et al., 2007). New patients with $\geq 75 \%$ arteriosclerosis were enrolled in this study.

\section{MATERIAL AND METHODS}

\section{Study population}

The study population consisted of 574 healthy controls (289 men and 285 women) and 559 patients with CAD (314 men and 245 women). The patients were enrolled between August 
2004 and December 2010 from the Department of Cardiology at the CHA Bundang Medical Center in Seongnam, South Korea. CAD was diagnosed based on the WHO criteria (Nomenclature and Criteria for Diagnosis of Ischemic Heart Disease, 1979). The patients had a history of one or more $75 \%$ stenosis in a major coronary artery. According to the Joint National Committee guidelines, HTN was defined as a diastolic pressure $>90 \mathrm{mmHg}$ and/or systolic pressure $>140 \mathrm{mmHg}$ while on hypertension medication (Chobanian et al., 2003). DM was defined as fasting glucose levels $>126 \mathrm{mg} / \mathrm{dL}$ or use of any diabetic medication (American Diabetes Association, 2004). The controls had no history of cardiovascular or cerebrovascular disease. This genetic study was approved by the Institutional Review Board of the hospital.

\section{Genetic analysis}

Three highly plausible candidate SNPs in the eNOS gene (GeneBank accession NO. NG 011992.1) were selected: -786T>C (rs2070744), intron4 4a4b (rs61722009), and 894G>T (rs1799983). Genomic DNA was extracted using the G-DEX blood extraction kit (Intron, Seongnam, Korea). The SNPs were identified by polymerase chain reaction (PCR)-restriction fragment length polymorphism (RFLP) using the isolated genomic DNA as a template. PCR samples were prepared using the Hotstart premix kit (Bioneer, Inc., Daejon, Korea). eNOS was genotyped as described previously (Kim et al., 2007).

\section{Estimation of homocysteine and folate concentrations}

Blood was collected in tubes containing an anticoagulant after $12 \mathrm{~h}$ of fasting. Samples were centrifuged for $15 \mathrm{~min}$ at $1,000 \times \mathrm{g}$ to separate the plasma from the whole blood. The plasma homocysteine and folate concentrations were measured using the IMx fluorescent polarizing immunoassay (Abbott Laboratories, Abbott Park, IL, USA) and a radioassay kit (ACS:180; Bayer, Tarrytown, NY, USA), respectively.

\section{Statistical analysis}

The Hardy-Weinberg equilibrium, allele frequencies, and expected genotype frequencies were calculated using the chi-square test. Data was analyzed using GraphPad prism 4.0 (GraphPad Software Inc., San Diego, CA, USA), MedCalc version 12.1.4 (MedCalc Software bvba, Mariakerke, Belgium), and the HAPSTAT program (v.3.0, www.bios.unc. edu/ lin/hapstat/). Risk analysis was performed by calculating the adjusted odds ratio (AOR) and $95 \%$ confidence intervals (Cls). A meta-analysis was performed with a random effects model (Jang et al., 2013).

\section{RESULTS}

The clinical and demographic characteristics of 559 CAD patients and 574 controls are presented in Table 1. Approximately half (50.3\% abd $56.2 \%)$ of the control and patient populations were male with a mean age of 60.55 and 60.36 years, respectively. The control and patient groups did not differ significantly with respect to the age, gender, or HTN. In contrast, DM and smoking were more frequent in CAD patients $(P<0.05)$. 
Table 1. Clinical and demographic characteristics of CAD patients and controls.

\begin{tabular}{lccc}
\hline Characteristic & Controls $(\mathrm{N}=574)$ & CAD patients $(\mathrm{N}=559)$ & $\mathrm{P}^{\mathrm{b}}$ \\
\hline Male [n (\%)] & $289(50.3)$ & $314(56.2)$ & 0.278 \\
Age $^{\mathrm{a}}$ & $60.55 \pm 11.56$ & $60.36 \pm 11.87$ & 0.845 \\
Hypertension [n (\%)] $_{\text {Diabetes mellitus [n (\%)] }}$ & $257(44.8)$ & $294(52.6)$ & 0.122 \\
Smoking [n (\%)] & $87(15.2)$ & $131(23.4)$ & 0.004 \\
\hline
\end{tabular}

$\mathrm{CAD}=$ coronary artery disease; ${ }^{\text {} Y e a r s ~ i n ~ m e a n ~} \pm$ standard deviation (SD); ${ }^{\mathrm{b}}$ Calculated using the Mann-Whitney test for continuous data and Chi-square test for categorical data.

The genotype distributions and allele frequencies of the eNOS $-786 \mathrm{~T}>\mathrm{C}, 4 \mathrm{a} 4 \mathrm{~b}$, and 894G $>$ T polymorphisms are summarized in Table 2 . The AORs were calculated using various risk factors including age, gender, HTN, DM, and smoking. The patients were classified based on whether or not they had undergone stent surgery. The non-stent surgery and stent surgery groups were named as groups $A$ and $B$, respectively. eNOS 894TT ( $A O R=4.301 ; 95 \% \mathrm{Cl}: 1.182-15.655)$ was associated with Group $A$; however, the various stratified analyses revealed no associations between Group B and the eNOS variants (Table S1).

The combined genotype frequencies of the eNOS -786T>C, 4a4b, and 894G>T polymorphisms in the CAD patients and controls are presented in Table 3. The combination of eNOS $-786 \mathrm{TT} / 4 \mathrm{a} 4 \mathrm{~b}+4 \mathrm{a} 4 \mathrm{a}(\mathrm{AOR}=0.122 ; 95 \% \mathrm{Cl}: 0.042-0.358)$ and eNOS $-786 \mathrm{TC}+\mathrm{CC} / 4 \mathrm{~b} 4 \mathrm{~b}(\mathrm{AOR}=0.379$; $95 \% \mathrm{Cl}: 0.147-0.979$ ) was significantly associated with CAD development. There were no statistically significant differences between the CAD patients and controls in other combined genotypes of the eNOS polymorphic site (Table 3). The eNOS $-786 \mathrm{TT} / 4 \mathrm{a} 4 \mathrm{~b}+4 \mathrm{a} 4 \mathrm{a}$ combination (Group A, AOR = 0.182; 95\% Cl: 0.043-0.779; Group B, AOR $=0.411 ; 95 \% \mathrm{Cl}: 0.179-0.945$ ) was associated with CAD. However, the eNOS $-786 \mathrm{TC}+\mathrm{CC} / 4 \mathrm{~b} 4 \mathrm{~b}$ combination was not associated with either group. Table S2 shows the results stratified according to the number of patients who underwent the stent surgery.

Haplotypes of two or three eNOS polymorphisms were constructed to identify the possible associations between specific haplotypes and CAD (Table 4). The T-4a-G (OR $=0.144 ; 95 \% \mathrm{Cl}$ : 0.050 0.414 ) haplotype frequency of $e N O S-786 \mathrm{~T}>\mathrm{C}, 4 \mathrm{a} 4 \mathrm{~b}$, and $894 \mathrm{G}>\mathrm{T}$ variants was significantly different between the CAD patients and controls. In addition, the T-4a haplotype of eNOS -786T $>C$ and $4 a 4 b$ was significantly different among the subjects. However, the associations of the $-786 \mathrm{~T} / 4 \mathrm{a} / 894 \mathrm{G}$ and $-786 \mathrm{~T} / 4$ a haplotype were diminished when stratified based on stent surgery. Table S3 shows the constructed haplotype frequencies, classified according to the number of patients who underwent the stent surgery. The serum homocysteine and folate levels in patients expressing the different genotypes are summarized in Table 5. The CAD patients expressing the eNOS -786TT and 4b4b genotypes, showed significantly reduced folate levels. These data indicate a protective effect for eNOS $-786 \mathrm{~T}>\mathrm{C}$ and $4 \mathrm{a} 4 \mathrm{~b}$ polymorphisms exerted a protective effect against CAD.

The results of the meta-analysis are summarized in Tables S4-S6. A total of 2014 controls and 2237 patients were positive for the eNOS $-786 \mathrm{~T}>\mathrm{C}$ polymorphism. The overall result shows the presence of an association between this polymorphism and CAD susceptibility $(\mathrm{OR}=1.571 ; 95 \% \mathrm{Cl}$ : 1.282-1.925; Table S4, Figure 1). A total of 1902 controls and 2027 patients were positive for the eNOS 4a4b polymorphism. The overall result shows the lack of any significant association between this polymorphism and CAD susceptibility (OR $=1.049 ; 95 \% \mathrm{Cl}: 0.862-1.275$; $\underline{\text { Table S5 }}$, Figure 2$)$; on other hand, 1760 controls and 2284 patients were positive for the eNOS 894G>T polymorphism, and the meta-analysis indicated an association between this polymorphism and CAD susceptibility (OR = 1.697; 95\% Cl: 1.241-2.322; Table S6, Figure 3). 
J.H. Sung et al.

16512

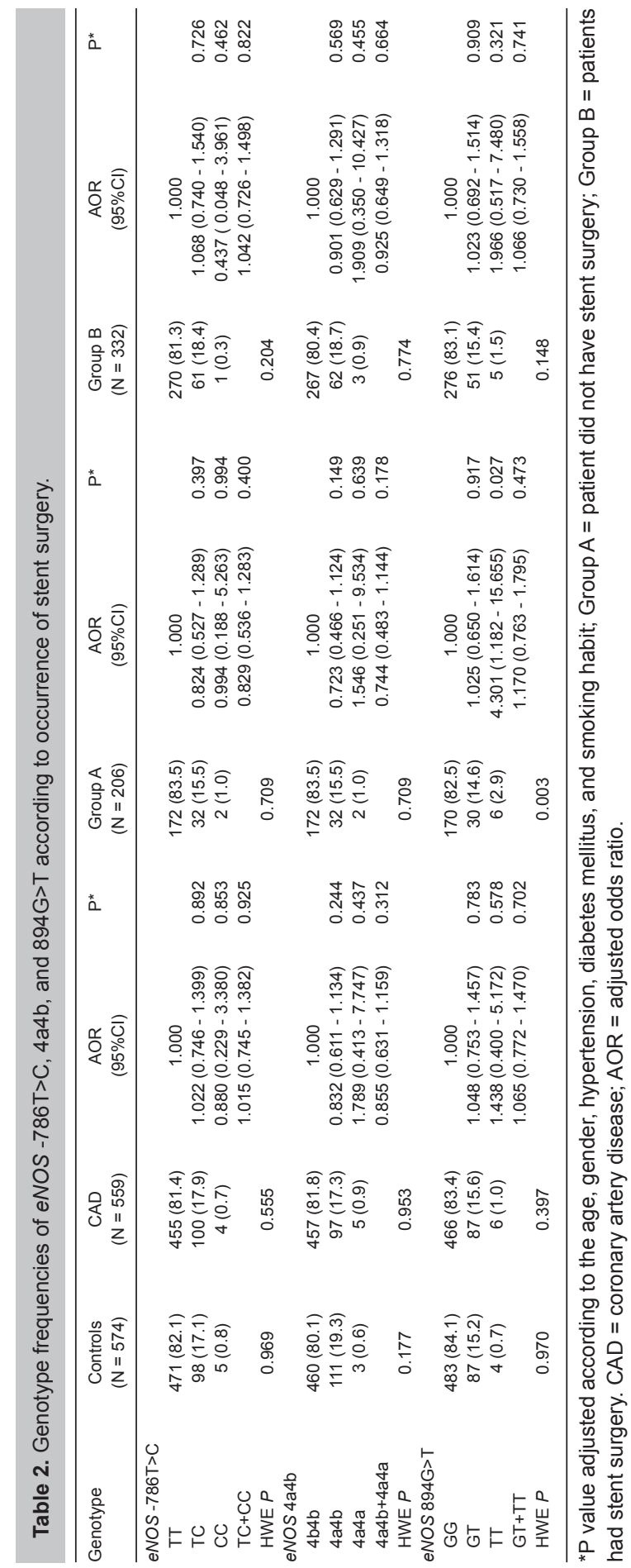

Genetics and Molecular Research 14 (4): 16508-16520 (2015) 
eNOS polymorphisms and CAD risk

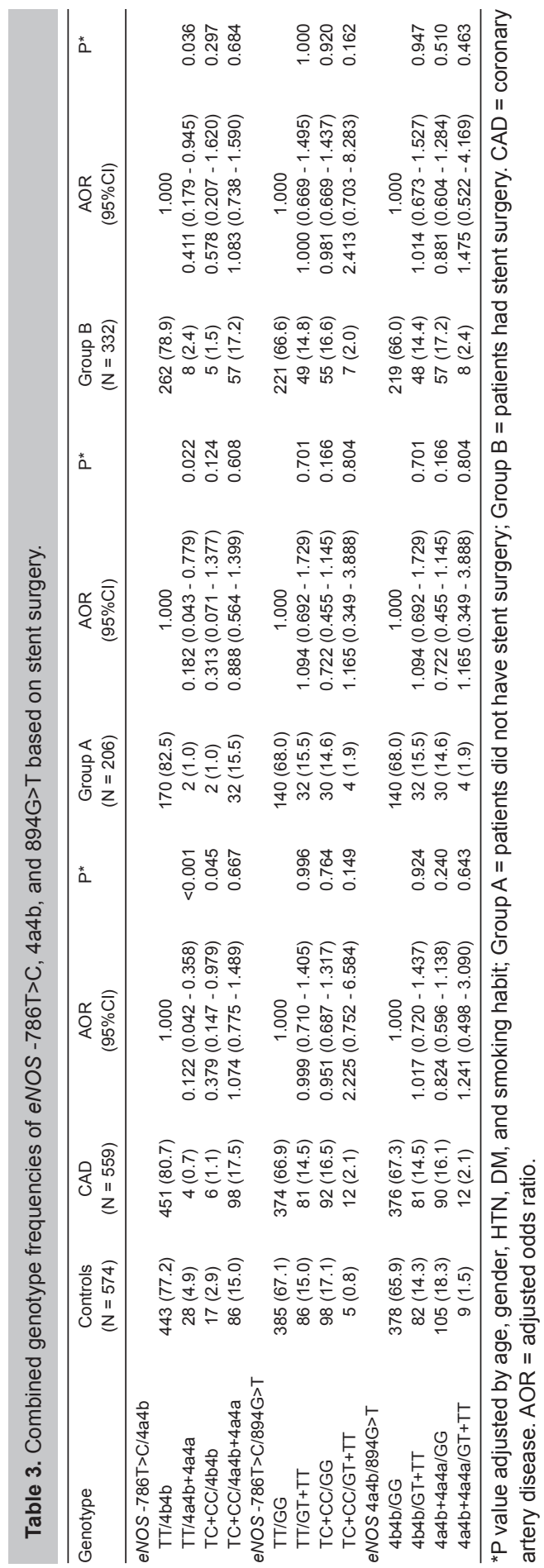


J.H. Sung et al.

16514

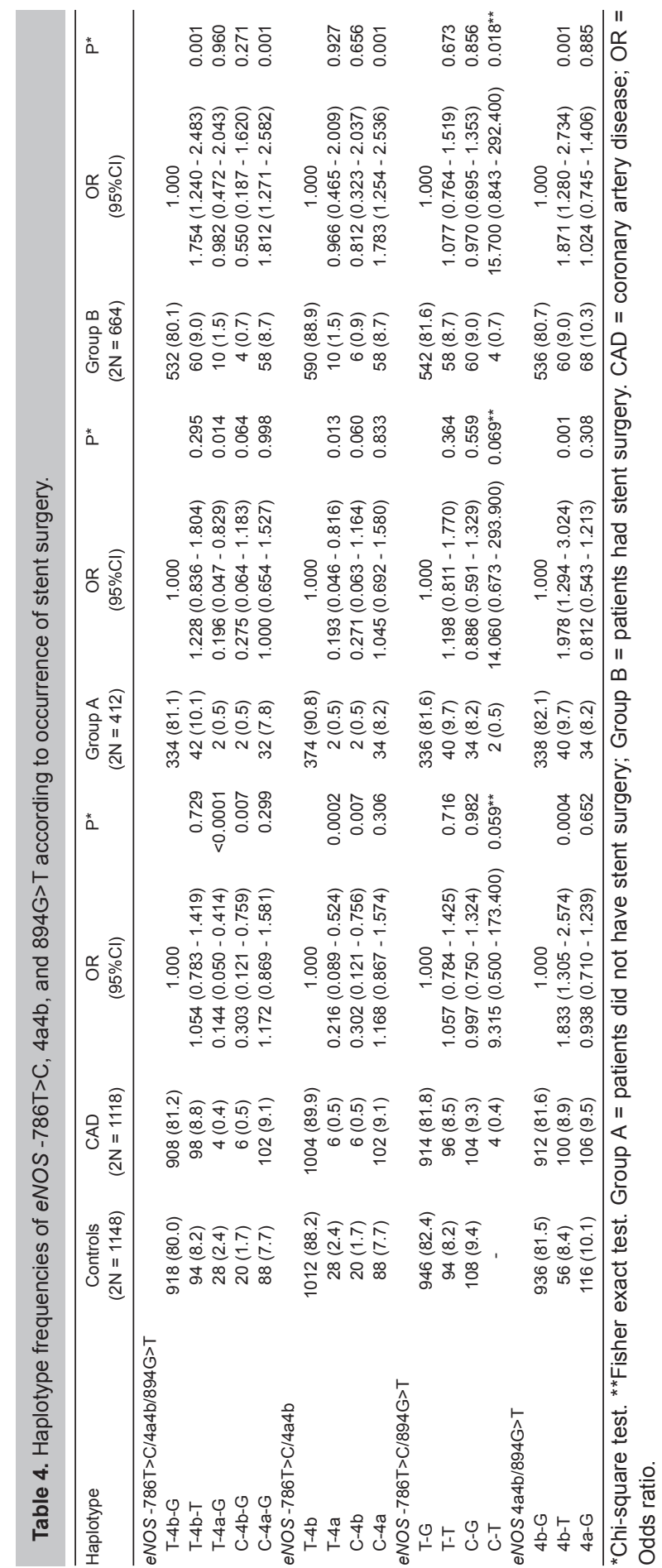

Genetics and Molecular Research 14 (4): 16508-16520 (2015)

(CFUNPEC-RP www.funpecrp.com.br 


\begin{tabular}{|c|c|c|c|c|c|c|c|}
\hline & $\begin{array}{c}\text { Controls } \\
(\text { mean } \pm S D)\end{array}$ & $\begin{array}{c}C A D \\
(\text { mean } \pm S D)\end{array}$ & $P$ & $\begin{array}{c}\text { Group A } \\
(\text { mean } \pm S D)\end{array}$ & $P$ & $\begin{array}{c}\text { Group B } \\
(\text { mean } \pm S D)\end{array}$ & $P$ \\
\hline \multicolumn{8}{|c|}{ Homocysteine $(\mu \mathrm{M})$} \\
\hline \multicolumn{8}{|c|}{ eNOS -786T >C } \\
\hline TT & $10.82 \pm 6.54$ & $10.08 \pm 4.95$ & 0.240 & $9.41 \pm 5.06$ & 0.001 & $10.34 \pm 4.60$ & 0.508 \\
\hline TC & $9.97 \pm 5.29$ & $10.14 \pm 5.61$ & 0.951 & $8.04 \pm 3.22$ & 0.057 & $11.26 \pm 6.30$ & 0.210 \\
\hline $\mathrm{CC}$ & NA & NA & NA & NA & NA & NA & NA \\
\hline \multicolumn{8}{|c|}{ eNOS 4a4b } \\
\hline $4 \mathrm{~b} 4 \mathrm{~b}$ & $10.72 \pm 6.53$ & $10.19 \pm 5.08$ & 0.628 & $9.43 \pm 5.07$ & 0.002 & $10.51 \pm 4.82$ & 0.163 \\
\hline $4 a 4 b$ & $10.52 \pm 5.50$ & $9.54 \pm 4.97$ & 0.091 & $7.97 \pm 3.20$ & 0.008 & $10.40 \pm 5.58$ & 0.691 \\
\hline $4 a 4 a$ & $7.41 \pm 2.10$ & $8.86 \pm 4.24$ & 1.000 & NA & NA & NA & NA \\
\hline \multicolumn{8}{|c|}{ eNOS 894G>T } \\
\hline GG & $10.87 \pm 6.76$ & $10.04 \pm 5.10$ & 0.158 & $8.89 \pm 4.34$ & $<0.0001$ & $1.57 \pm 5.22$ & 0.445 \\
\hline GT & $9.51 \pm 2.86$ & $10.15 \pm 4.94$ & 0.667 & $10.45 \pm 6.91$ & 0.745 & $10.06 \pm 3.41$ & 0.321 \\
\hline $\mathrm{TT}$ & $10.29 \pm 1.88$ & $10.99 \pm 4.58$ & 0.744 & $11.49 \pm 5.55$ & 0.914 & $10.39 \pm 3.62$ & 0.730 \\
\hline \multicolumn{8}{|c|}{ Folate (nM) } \\
\hline \multicolumn{8}{|c|}{ eNOS -786T >C } \\
\hline TT & $8.33 \pm 5.44$ & $7.78 \pm 6.91$ & $<0.001$ & $7.39 \pm 5.70$ & 0.002 & $8.27 \pm 7.80$ & 0.011 \\
\hline TC & $10.22 \pm 8.50$ & $10.25 \pm 16.0$ & 0.182 & $8.35 \pm 4.49$ & 0.350 & $11.36 \pm 20.09$ & 0.187 \\
\hline $\mathrm{CC}$ & NA & NA & NA & NA & NA & NA & NA \\
\hline \multicolumn{8}{|c|}{ eNOS 4a4b } \\
\hline $4 \mathrm{~b} 4 \mathrm{~b}$ & $8.35 \pm 5.27$ & $7.74 \pm 6.91$ & $<0.0001$ & $7.41 \pm 5.71$ & 0.002 & $8.19 \pm 7.80$ & 0.004 \\
\hline $4 a 4 b$ & $9.91 \pm 8.70$ & $10.49 \pm 15.93$ & 0.645 & $8.25 \pm 4.44$ & 0.488 & $11.84 \pm 20.03$ & 0.793 \\
\hline $4 a 4 a$ & NA & NA & NA & NA & NA & NA & NA \\
\hline \multicolumn{8}{|c|}{ eNOS 894G>T } \\
\hline GG & $8.59 \pm 6.15$ & $8.55 \pm 9.69$ & 0.006 & $7.71 \pm 5.84$ & 0.011 & $9.37 \pm 11.58$ & 0.150 \\
\hline GT & $9.18 \pm 5.87$ & $6.33 \pm 3.71$ & $<0.001$ & $6.51 \pm 3.33$ & 0.024 & $6.26 \pm 4.01$ & 0.001 \\
\hline $\mathrm{TT}$ & $6.98 \pm 2.40$ & $6.01 \pm 4.61$ & 0.215 & $7.56 \pm 5.73$ & 0.762 & $4.16 \pm 2.05$ & 0.064 \\
\hline
\end{tabular}

$\mathrm{CAD}=$ coronary artery disease.

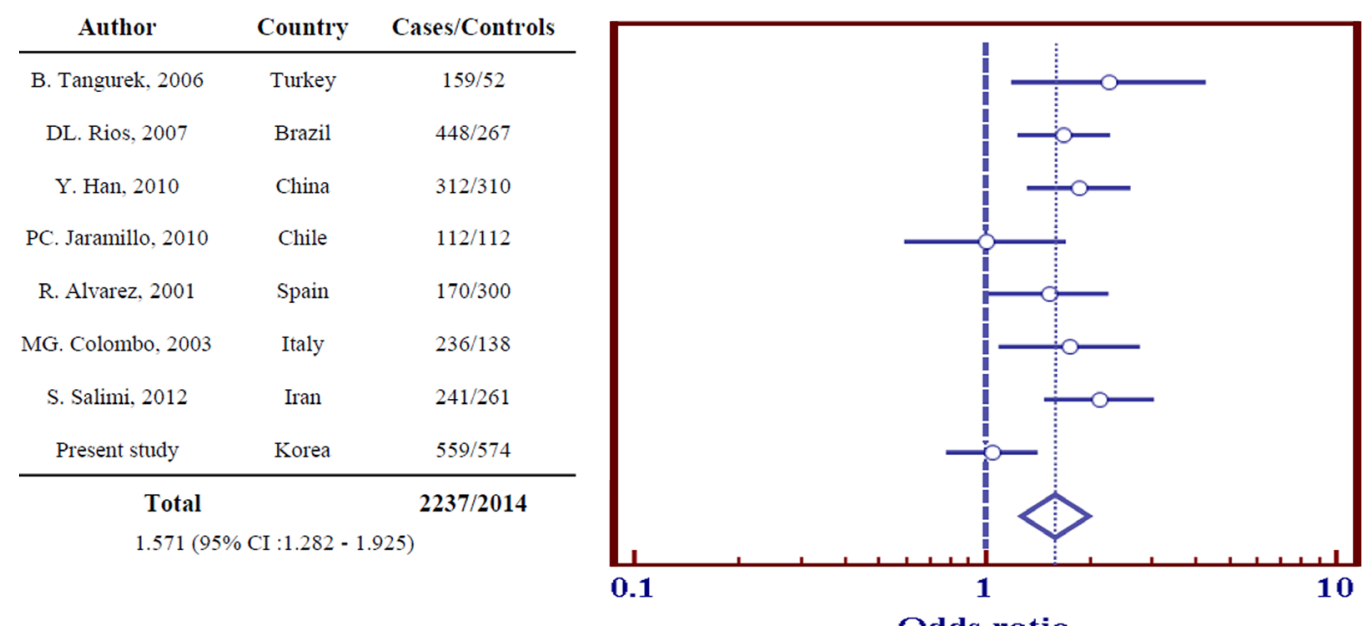

\section{Odds ratio}

Figure 1. Meta-analysis of the association between carriers of the $C$ allele (individuals with TC $+C C$ genotypes) of the eNOS -786T $>C$ polymorphism and coronary artery disease (CAD). A random effects model was used to calculate the pooled weighted odds ratio $(\mathrm{OR})$.

Linkage disequilibrium of the eNOS polymorphisms at loci -786T>C (rs2070744)/4a4b (rs61722009)/894G>T (rs1799983) in patients with CAD is shown in Figure 4. We observed a strong linkage disequilibrium between loci -786T $>C$ and $-4 a 4 b\left(D^{\prime}=0.802\right),-786 T>C$ and $894 G>T$ $\left(D^{\prime}=0.856\right)$, and $786 T>C$ and $4 a 4 b\left(D^{\prime}=1.000\right)$ in patients with CAD. 


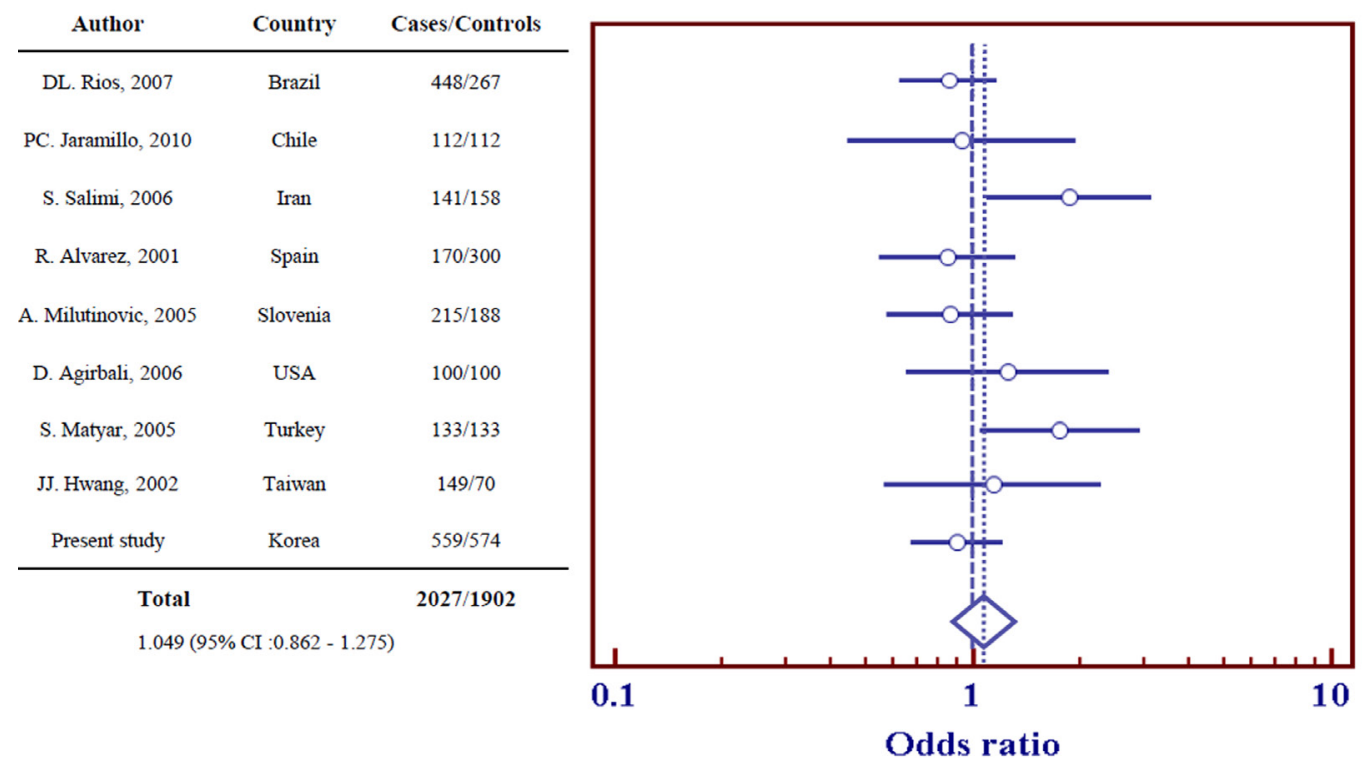

Figure 2. Meta-analysis of the association between carriers of the $4 a$ allele (individuals with the $4 a 4 b+4 a 4 a$ genotypes) of the eNOS $4 \mathrm{a} 4 \mathrm{~b}$ polymorphism and coronary artery disease (CAD). A random effects model was used to calculate the pooled weighted odds ratio (OR).

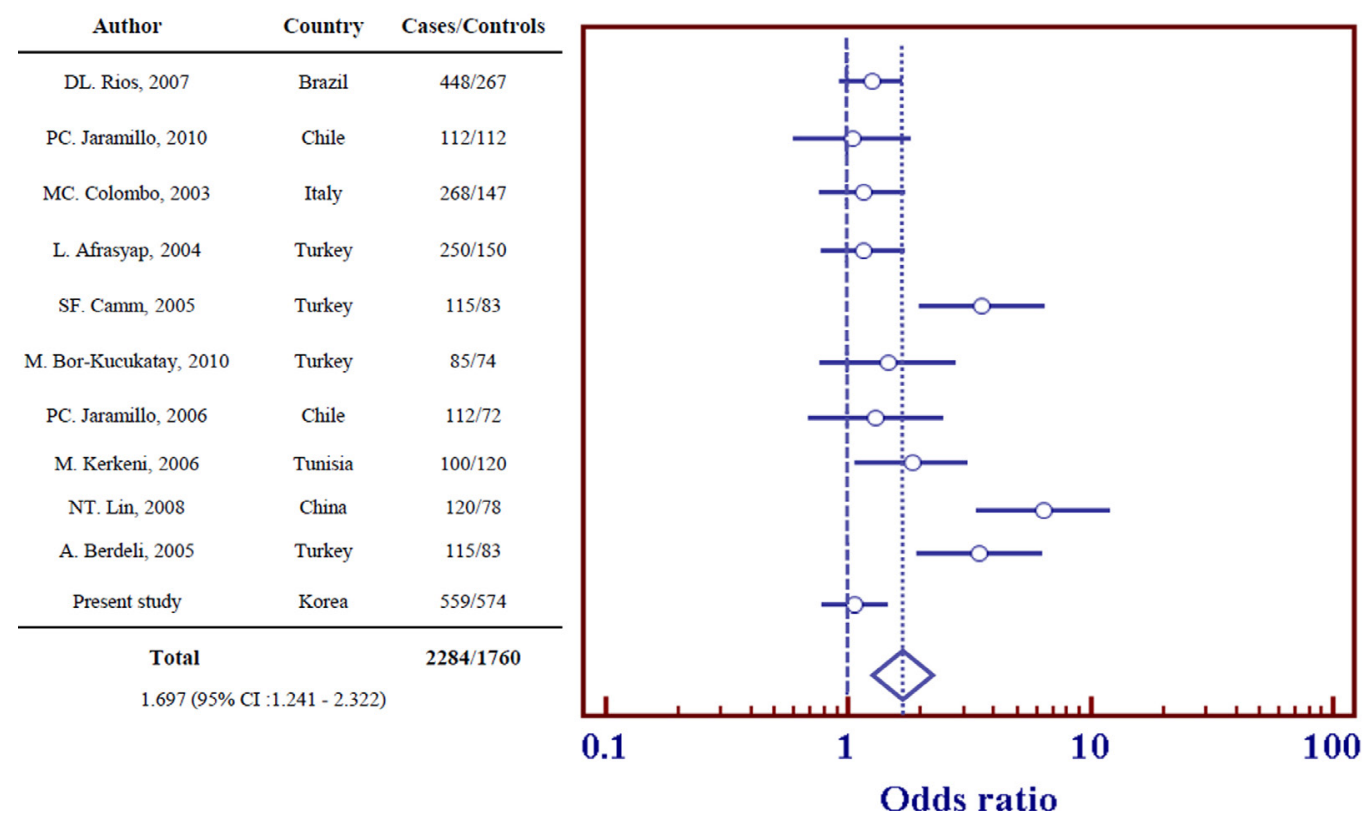

Figure 3. Meta-analysis of the association between carriers of the T allele (individuals with the GT + TT genotypes) of the eNOS $894 \mathrm{G}>\mathrm{T}$ polymorphism and coronary artery disease (CAD). A random effects model was used to calculate the pooled weighted odds ratio $(\mathrm{OR})$. 


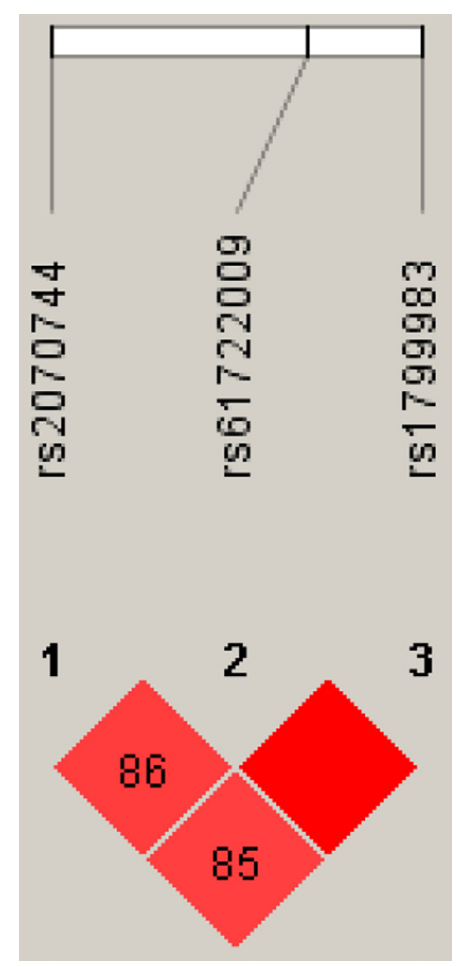

Figure 4. Linkage disequilibrium (LD) patterns of the eNOS polymorphisms. We observed strong LDs between loci -786T>C (rs2070744) and 4a4b (rs61722009; D'=0.802), -786T>C (rs2070744) and 894G>T (rs1799983; D'=0.856), and 4a4b (rs61722009) and 894G>T (rs1799983; $\left.D^{\prime}=1.000\right)$ in patients with coronary artery disease (CAD).

\section{DISCUSSION}

Endothelium-derived NO inhibits the aggregation of platelets (Furlong et al., 1987; Yao et al., 1992). Nitric oxide also protects against mitogenesis and proliferation of vascular smooth muscle cells (Garg and Hassid, 1989). Inhibition of nitric oxide synthesis for a long period of time has been reported to promotes atherosclerosis in the hypercholesterolemic rabbit thoracic aorta (Naruse et al., 1994). In-stent restenosis is the secondary proliferation of neointima into the stent (Currier and Faxon, 1995; Hoffmann et al., 1996; Mintz et al., 1996).

The eNOS -786T>C polymorphism is located in the promoter region. This mutation, first observed in patients with coronary vasospasm, inhibits the eNOS promoter transcription activity (Nakayama et al., 2000), in turn reducing the NO production in blood vessels and endothelial dysfunction (Kim et al., 2007).

The $4 a 4 b$ polymorphism is a $27-b p$ repeat polymorphism in the intron 4 region of the eNOS gene. The $4 \mathrm{a}$ allele has been shown to induce smoking-dependent coronary risk in Australian Caucasians, was well as increases plasma NO levels in the blood vessels (Wang et al., 1997; Kim et al., 2007). However, other studies have found no correlation between genetic polymorphisms and plasma NO concentration (Yoon et al., 2000). This variant is unlikely to be functional and act as a marker in linkage disequilibrium with other functional variants (Casas et al., 2004). 
The eNOS 894G>T polymorphism is located in the exon 7 region, and causes the replacement of glutamate with aspartate (Glu298Asp). This variant was suggested to be a contributing factor for coronary spasm, acute myocardial infarction, and the development of CAD (Hibi et al., 1998; Shimasaki et al., 1998; Yoshimura et al., 1998; Hingorani et al., 1999; Colombo et al., 2002, 2003). eNOS $894 \mathrm{G}>\mathrm{T}$ is also a genetic risk factor for in-stent restenosis (Suzuki et al., 2002).

In our previous study, an association was established between the eNOS -786T>C and $4 \mathrm{a} 4 \mathrm{~b}$ polymorphisms and increased risk of CAD in the Korean population, while $894 \mathrm{G}>\mathrm{T}$ showed no such association. In this study, eNOS -786T $>\mathrm{C}$ and $4 \mathrm{a} 4 \mathrm{~b}$ displayed a protective effect against CAD development. In addition, 894TT was associated with a mild risk of CAD. Therefore, eNOS polymorphisms may contribute to $C A D$ risk under certain conditions. We also performed a metaanalysis of the published studies investigating the genetic association between eNOS and the risk of CAD; no association was found between eNOS -786T>C and eNOS 4a4b and CAD. However, this meta-analysis revealed that eNOS $894 \mathrm{G}>\mathrm{T}$ increased the risk of CAD. The sample size (number of included studies) of this meta-analysis was small; therefore we cannot rule out the possibility of the results being affected, although no significant publication bias was found.

\section{CONCLUSION}

In our previous study, we identified an association between CAD and eNOS -786T>C and $4 \mathrm{a} 4 \mathrm{~b}$. However, in a larger population, these associations were diminished; in addition, some combined genotypes showed a protective effect against CAD risk. Therefore, the relationship between eNOS polymorphisms and CAD risk must be carefully analyzed.

\section{CONFLICT OF INTEREST}

The authors declare no conflict of interest.

\section{ACKNOWLEDGMENTS}

Research supported by funds provided by the Basic Science Research Program (\#NRF2013R1A1A2008177 and \#NRF-2012R1A1A2007033 \& \#2009-0093821) through the National Research Foundation of Korea (NRF), funded by the Ministry of Education, Republic of Korea.

\section{Supplementary Material}

\section{REFERENCES}

American Diabetes Association (2004). Diagnosis and classification of diabetes mellitus. Diabetes Care 27: S5-S10.

Cam SF, Sekuri C, Tengiz I, Ercan E, et al. (2005). The G894T polymorphism on endothelial nitric oxide synthase gene is associated with premature coronary artery disease in a Turkish population. Thromb. Res. 116: 287-292.

Casas JP, Bautista LE, Humphries SE and Hingorani AD (2004). Endothelial nitric oxide synthase genotype and ischemic heart disease: meta-analysis of 26 studies involving 23028 subjects. Circulation 109: 1359-1365.

Chaer RA, Billeh R and Massad MG (2004). Genetics and gene manipulation therapy of premature coronary artery disease. Cardiology 101: 122-130.

Chobanian AV, Bakris GL, Black HR, Cushman WC, et al. (2003). The seventh report of the joint national committee on prevention, detection, evaluation, and treatment of high blood pressure: the JNC 7 report. JAMA 289: 2560-2572. 
Colombo MG, Andreassi MG, Paradossi U, Botto N, et al. (2002). Evidence for association of a common variant of the endothelial nitric oxide synthase gene (Glu298Asp polymorphism) to the presence, extent and severity of coronary artery disease. Heart 87: 525-528.

Colombo MG, Paradossi U, Andreassi MG, Botto N, et al. (2003). Endothelial nitric oxide synthase gene polymorphisms and risk of coronary artery disease. Clin. Chem. 49: 3389-3395.

Currier JW and Faxon DP (1995). Restenosis after percutaneous transluminal coronary angioplasty: have we been aiming at the wrong target? J. Am. Coll. Cardiol. 25: 516-520.

Furlong B, Henderson AH, Lewis MJ and Smith JA (1987). Endothelium-derived relaxing factor inhibits in vitro platelet aggregation. Br. J. Pharmacol. 90: 687-692.

Gardemann A, Lohre J, Cayci S, Katz N, et al. (2002). The T allele of the missense Glu(298)Asp endothelial nitric oxide synthase gene polymorphism is associated with coronary heart disease in younger individuals with high atherosclerotic risk profile. Atherosclerosis 160: 167-175.

Garg UC and Hassid A (1989). Nitric oxide-generating vasodilators and 8-bromo-cyclic guanosine monophosphate inhibit mitogenesis and proliferation of cultured rat vascular smooth muscle cells. J. Clin. Invest. 83: 1774-1777.

Han Y, Xu W, Zhang W, Liu N, et al. (2010). T-786C polymorphism in the endothelial nitric oxide synthase gene is associated with increased risk of coronary artery disease in a Chinese population. Pharmacology 85: 211-216.

Hibi K, Ishigami T, Tamura K, Mizushima S, et al. (1998). Endothelial nitric oxide synthase gene polymorphism and acute myocardial infarction. Hypertension 32: 521-526.

Hingorani AD, Liang CF, Fatibene J, Lyon A, et al. (1999). A common variant of the endothelial nitric oxide synthase (Glu298Asp) is a major risk factor for coronary artery disease in the UK. Circulation 100: 1515-1520.

Hoffmann R, Mintz GS, Dussaillant GR, Popma JJ, et al. (1996). Patterns and mechanisms of in-stent restenosis. A serial intravascular ultrasound study. Circulation 94: 1247-1254.

Huang PL, Huang Z, Mashimo H, Bloch KD, et al. (1995). Hypertension in mice lacking the gene for endothelial nitric oxide synthase. Nature 377: 239-242.

Jang MJ, Jeon YJ, Choi WI, Choi YS, et al. (2013). The 677C>T mutation of the MTHFR gene increases the risk of venous thromboembolism in Koreans and a meta-analysis from Asian population. Clin. Appl. Thromb. Hemost. 19: 309-314.

Kim IJ, Bae J, Lim SW, Cha DH, et al. (2007). Influence of endothelial nitric oxide synthase gene polymorphisms (-786T>C, 4a4b, 894G>T) in Korean patients with coronary artery disease. Thromb. Res. 119: 579-585.

Marsden PA, Heng HH, Scherer SW, Stewart RJ, et al. (1993). Structure and chromosomal localization of the human constitutive endothelial nitric oxide synthase gene. J. Biol. Chem. 268: 17478-17488.

Mintz GS, Popma JJ, Hong MK, Pichard AD, et al. (1996). Intravascular ultrasound to discern devise-specific effects and mechanisms of restenosis. Am. J. Cardiol. 78: 18-22.

Miyamoto Y, Saito Y, Nakayama M, Shimasaki Y, et al. (2000). Replication protein A1 reduces transcription of the endothelial nitric oxide synthase gene containing a $-786 \mathrm{~T}->\mathrm{C}$ mutation associated with coronary spastic angina. Hum. Mol. Genet. 9: $2629-2637$.

Moncada S and Higgs A (1993). The L-arginine-nitric oxide pathway. N. Engl. J. Med. 329: 2002-2012.

Nakayama M, Yasue H, Yoshimura M, Shimasaki Y, et al. (2000). T(-786)-> C mutation in the 5'-flanking region of the endothelial nitric oxide synthase gene is associated with myocardial infarction, especially without coronary organic stenosis. Circulation 86: 628-634.

Naruse K, Shimizu K, Muramatsu M, Toki Y, et al. (1994). Long-term inhibition of NO synthesis promotes atherosclerosis in the hypercholesterolemic rabbit thoracic aorta: $\mathrm{PGH}$ does not contribute to impaired endothelium-dependent relaxation. Arterioscler. Thromb. 14: 746-752.

Nomenclature and Criteria for Diagnosis of Ischemic Heart Disease (1979). Report of the Joint International Society and Federation of Cardiology/World Health Organization Task Force on Standardization of Clinical Nomenclature. Circulation 59: 607-609.

Ohashi Y, Kawashima S, Hirata K, Yamashita T, et al. (1998). Hypotension and reduced nitric oxide elicited vasorelaxation in transgenic mice overexpressing endothelial nitric oxide synthase. J. Clin. Invest. 102: 2061- 2071.

Palmer RM (1993). The L-arginine: nitric oxide pathway. Curr. Opin. Nephrol. Hypertens. 2: 122-128.

Rios DL, D'Onofrio LO, Souza JK, Queiroz AM, et al. (2007). Smoking-dependent and haplotype-specific effects of endothelial nitric oxide synthase gene polymorphisms on angiographically assessed coronary artery disease in Caucasian- and African-Brazilians. Atherosclerosis 193: 135-141.

Shimasaki Y, Yasue H, Yoshimura M, Nakayama M, et al. (1998). Association of the missense Glu298 Asp variant of the endothelial nitric oxide synthase gene with myocardial infarction. J. Am. Coll. Cardiol. 31: 1506-1510.

Suzuki T, Okumura K, Sone T, Kosokabe T, et al. (2002). The Glu298Asp polymorphism in endothelial nitric oxide synthase gene is associated with coronary in-stent restenosis. Int. J. Cardiol. 86: 71-76. 
Tangurek B, Ozer N, Sayar N, Terzi S, et al. (2006). The relationship between endothelial nitric oxide synthase gene polymorphism (T-786C) and coronary artery disease in the Turkish population. Heart Ves. 21: 285-290.

Visvikis-Siest S and Marteau JB (2006). Genetic variants predisposing to cardiovascular disease. Curr. Opin. Lipidol. 17: 139151.

Wang XL, Sim AS, Badenhop RF, McCredie RM, et al. (1996). A smoking-dependent risk of coronary artery disease associated with a polymorphism of the endothelial nitric oxide synthase gene. Nat. Med. 2: 41-45.

Wang XL, Mahaney MC, Sim AS, Wang J, et al. (1997). Genetic contribution of the endothelial constitutive nitric oxide synthase gene to plasma nitric oxide levels. Arterioscler. Thromb. Vasc. Biol. 17: 3147-3153.

Yao SK, Ober JC, Krishnaswami A, Ferguson JJ, et al. (1992). Endogenous nitric oxide protects against platelet aggregation and cyclic flow variations in stenosed and endothelium-injured arteries. Circulation 86: 1302-1309.

Yoon Y, Song J, Hong SH and Kim JQ (2000). Plasma nitric oxide concentrations and nitric oxide synthase gene polymorphisms in coronary artery disease. Clin. Chem. 46: 1626-1630.

Yoshimura M, Yasue H, Nakayama M, Shimasaki Y, et al. (1998). A missense Glu298Asp variant in the endothelial nitric oxide synthase gene is associated with coronary spasm in the Japanese. Hum. Genet. 103: 65-69. 